\title{
Long noncoding RNA XIST expedites metastasis and modulates epithelial-mesenchymal transition in colorectal cancer
}

\author{
Dong-liang Chen ${ }^{1,3}$, Le-zong Chen ${ }^{1,3}$, Yun-xin Lu ${ }^{1,3}$, Dong-sheng Zhang ${ }^{1}$, Zhao-lei Zeng ${ }^{1}$, Zhi-zhong Pan ${ }^{1}$, Peng Huang ${ }^{2}$, \\ Feng-hua Wang ${ }^{1}$, Yu-hong $\mathrm{Li}^{1}$, Huai-qiang $\mathrm{Ju}^{*, 1}$ and Rui-hua $\mathrm{Xu}^{\star, 1}$
}

Tumor progression and metastasis is the main cause of death in colorectal cancer (CRC). Long noncoding RNAs (IncRNAs) are critical regulators in various diseases including human cancer. In this study, we found that IncRNA XIST was overexpressed in CRC cell lines and tissues. High expression of IncRNA XIST was associated with adverse overall survival in CRC patients. Knockdown of IncRNA XIST remarkably inhibited CRC cell proliferation, invasion, epithelial-mesenchymal transition (EMT) and CRC stem cell formation in vitro as well as tumor growth and metastasis in vivo. Further study indicated that knockdown of IncRNA XIST markedly increased the expression of microRNA-200b-3p (miR-200b-3p) that has been found to be downregulated in CRC tissues and cell lines, and luciferase activity assay indicated that IncRNA XIST could bind directly with miR-200b-3p. Moreover, knockdown of IncRNA XIST significantly reduced the expression of ZEB1, which was the direct target of miR-200b-3p, and the tumor suppressive effects caused by knockdown of IncRNA XIST could be rescued by re-expression of ZEB1 in CRC cells. Overall, our study demonstrated how IncRNA XIST regulates CRC progression and metastasis by competing for miR-200b-3p to modulate the expression of ZEB1. IncRNA XIST may be used as a biomarker to predict prognosis in CRC patients.

Cell Death and Disease (2017) 8, e3011; doi:10.1038/cddis.2017.421; published online 24 August 2017

Globally, colorectal cancer (CRC) is one of the most common malignancies and the third leading cause of cancer-related deaths. ${ }^{1}$ Tumor progression and metastasis are the main causes of deaths of CRC, especially for advanced-stage patients. Despite recent progresses in the therapeutic strategies for $\mathrm{CRC}$, including targeted therapies and immunotherapy, the prognosis for advanced-stage patients is still far from satisfactory. Tumor metastasis is a complex process in which the tumor cells acquire enhanced invasion abilities, and then invade into the circulation and finally colonize in the distant organ, and the critical event in this process is the accumulation of multiple genetic and epigenetic alterations that lead to the activation or inactivation of different genes. ${ }^{2}$ Therefore, there is an urgent need to identify the molecular mechanism of CRC progression and metastasis.

In recent years it has been recognized that the vast majority of mammalian genome are transcribed to produce noncoding RNAs (ncRNAs), among which are a group of transcripts called long noncoding RNAs (IncRNAs) that are abundantly expressed in different diseases and are involved in the regulation of tumors. ${ }^{3}$ IncRNAs are defined as a class of ncRNA with length $>200$ nucleotides with no or limited protein-coding capacity. ${ }^{4}$ Increasing evidences demonstrated that IncRNAs play important roles in regulating multiple biological process including cell proliferation, cell differentiation, cell invasion and chromosome inactivation. ${ }^{5-7}$ According to the structure and function, IncRNAs can be classified into several groups, including transcripts, antisense, circular RNAs, long intergenic ncRNAs (lincRNAs) and pseudogenes, and they can act as guides, scaffolds, tethers and decoys of other molecules, thus regulating multiple biological processes. $^{8,9}$ Some IncRNAs have been found to be expressed aberrantly in CRC tissues compared with normal epithelial tissue, and these IncRNAs are involved in regulating tumor phenotype by modulating the expression of their target genes. $^{10}$

IncRNA XIST (X-inactive specific transcript) is a product of the XIST gene and the master regulator of $X$ inactivation in mammals. Increasing studies indicated that IncRNA XIST is frequently dysregulated in multiple tumors and affects the tumor phenotypes. ${ }^{11-13}$ However, the role and molecular mechanism of IncRNA XIST in CRC development and metastasis is still unknown.

In this study, we found that IncRNA XIST was significantly upregulated in CRC tissues and cell lines. Overexpression of IncRNA XIST was associated with poor overall survival. Knockdown of IncRNA XIST suppressed cell proliferation, invasion, epithelial-mesenchymal transition (EMT) and stem cell formation in vitro as well as tumor growth and metastasis in vivo. Further investigation revealed that IncRNA XIST could act as a ceRNA for microRNA-200b-3p (miR-200b-3p) to modulate the expression of ZEB1.

\footnotetext{
${ }^{1}$ State Key Laboratory of Oncology in South China, Collaborative Innovation Center for Cancer Medicine, Sun Yat-sen University Cancer Center, Guangzhou, China and ${ }^{2}$ University of Texas MD Anderson Cancer Center, Houston, TX, USA

*Corresponding author: H-q Ju or R-h Xu, Department of Medical Oncology, State Key Laboratory of Oncology in South China, Collaborative Innovation Center for Cancer Medicine, Sun Yat-sen University Cancer Center, No. 651 Dong Feng East Road, Guangzhou 510060, China. Tel: +86 2087342280 or +86 2087343333 ; Fax: +86 20 87343008 or +86 20 87343295; E-mail: juhq@ sysucc.org.cn or xurh@sysucc.org.cn

${ }^{3}$ These authors contributed equally to this work.

Received 22.5.17; revised 17.7.17; accepted 24.7.17; Edited by R Johnstone
} 

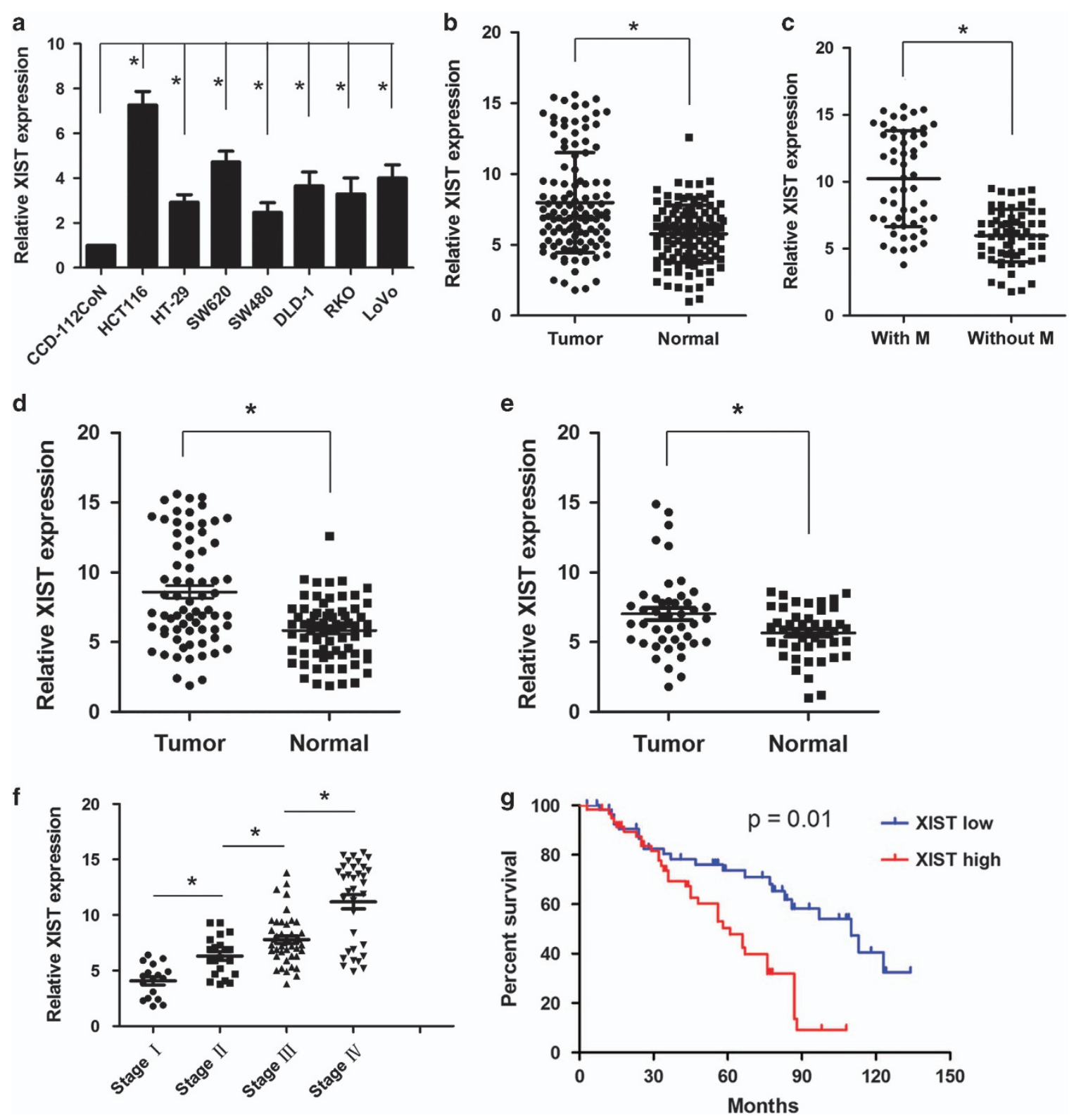

Figure 1 IncRNA XIST is significantly upregulated in CRC cell lines and tissues. (a) Relative expression level of IncRNA XIST in CRC cell lines $\left({ }^{*} P<0.05\right)(n=3$ independent experiments). (b) Relative expression of IncRNA XIST expression in CRC tissues $(n=115)$ and adjacent normal tissues $(n=115)\left({ }^{*} P<0.05\right)(n=3$ independent experiments). (c) Relative expression level of IncRNA XIST in CRC tissues with $(n=54)$ and without distant metastasis $(n=61)\left({ }^{*} P<0.05\right)(n=3$ independent experiments). (d) Relative expression level of IncRNA XIST in 70 male CRC tissues and the adjacent normal tissues $\left({ }^{*} P<0.05\right)(n=3$ independent experiments). (e) Relative expression level of IncRNA XIST in 45 female CRC tissues and adjacent normal tissues ( $\left.{ }^{*} P<0.05\right)(n=3$ independent experiments). (f) Relative expression level of IncRNA XIST in different clinical stages $\left({ }^{\star} P<0.05\right)(n=3$ independent experiments). (g) Kaplan-Meier analysis of overall survival in CRC patients with high IncRNA XIST level $(n=58)$ and low IncRNA XIST level $(n=57)(P=0.01)$. Error bars represent the mean \pm S.D. values

\section{Results}

IncRNA XIST expression is upregulated in CRC cell lines and tissues. First, the expression of IncRNA XIST was measured in CRC cell lines, compared with the normal colon epithelial cell line CCD-112CoN, and IncRNA XIST was significantly upregulated in CRC cell lines $\left({ }^{\star} P<0.05\right.$, Figure 1a). IncRNA XIST expression was then measured in 115 patients with CRC tissues and paired normal tissues. Compared with adjacent normal tissues, IncRNA XIST expression was significantly upregulated in $\mathrm{CRC}$ tissues $\left({ }^{*} P<0.05\right.$, Figure $\left.1 \mathrm{~b}\right)$. Moreover, IncRNA XIST was higher in tumors with distant metastasis than tumors without distant metastasis $\left({ }^{*} P<0.05\right.$, Figure $\left.1 \mathrm{c}\right)$. Previous studies have found that IncRNA plays an important role in X-chromosome inactivation, and we wondered whether gender difference exists in the expression pattern of IncRNA XIST. The result showed that in both male and female patients, the expression of IncRNA XIST was significantly higher in tumor tissues than that of adjacent normal tissues $\left({ }^{\star} P<0.05\right.$, Figures $1 \mathrm{~d}$ and $\left.\mathrm{e}\right)$. 
In addition, IncRNA XIST expression was significantly increased in advanced clinical stages than that of low stages $\left({ }^{\star} P<0.05\right.$, Figure 1f). To further explore the prognostic significance of IncRNA XIST in CRC, the 115 patients were classified into two groups (high expression and low expression group) according to the median level of relative IncRNA XIST expression in tumor tissues. IncRNA XIST expression was significantly associated with tumor size $(P=0.001)$, histological grade $(P=0.018)$, distant metastasis $(P=0.001)$ and TNM stage $(P=0.006)$ (Supplementary Table $S 1)$. Survival analysis was evaluated using the Kaplan-Meier method and assessed using the log-rank test. As a result, patients with higher IncRNA XIST expression had worse overall survival than those with lower IncRNA XIST expression $\left({ }^{\star} P=0.01\right.$, Figure $\left.1 \mathrm{~g}\right)$. Univariate analysis indicated that other clinical and pathological parameters such as lymph node invasion $(P=0.047)$, distant metastasis $(P=0.025)$ and TNM stage $(P=0.021)$ were also significantly associated with patients' prognosis, but multivariate analysis demonstrated that only IncRNA XIST expression $(P=0.039)$ and distant metastasis $(P=0.033)$ were independent prognostic factors for CRC patients (Supplementary Table S2).

Knockdown of IncRNA XIST inhibits cell proliferation, migration and invasion in vitro. Having demonstrated that IncRNA XIST is involved in CRC progression, we wondered whether IncRNA XIST is required for maintenance of malignant phenotype of CRC cells. Knockdown of IncRNA XIST resulted in significant reduction of IncRNA XIST level in HCT116 and SW620 cells. CCK-8 assay showed that knockdown of IncRNA XIST markedly inhibited cell proliferation rate in HCT116 and SW20 cells $\left({ }^{\star} P<0.05\right.$, Figure $\left.2 \mathrm{a}\right)$. Colony formation assay indicated that knockdown of IncRNA XIST significantly suppressed colony formation in HCT116 and SW620 cells ( ${ }^{\star} P<0.05$, Figure $2 \mathrm{~b}$ ). Moreover, wound healing assay showed a significant reduction of cell migration after knockdown of IncRNA XIST in HCT116 and SW620 cells ( ${ }^{*} P<0.05$, Figure $2 \mathrm{c}$ ), and transwell assay indicated that knockdown of IncRNA XIST inhibited cell invasion of HCT116 and SW620 cells ( ${ }^{\star} P<0.05$, Figure $2 \mathrm{~d}$ ).

Knockdown of IncRNA XIST inhibits EMT and stem cell formation in CRC cells. It has been reported that EMT is a critical step of tumor metastasis. We therefore investigated whether IncRNA XIST could modulate EMT in CRC cells. The results indicated that HCT116 cells underwent morphological change from a spindle shape to a rounded or cobblestonelike shape upon knockdown of IncRNA XIST (Figure 3a), and knockdown of IncRNA XIST could significantly increase the expression of E-cadherin but decrease the expression of $\mathrm{N}$-cadherin in SW620 cells as demonstrated by immunofluorescence (Figure 3b). Moreover, real-time PCR analysis also confirmed that knockdown of IncRNA XIST significantly reduced the expression of mesenchymal markers ( $\mathrm{N}$-cadherin, Vimetin, Snail, Slug) but increased the expression of epithelial markers (E-cadherin, $\alpha$-catenin, $\beta$-catenin) $\left({ }^{\star} P<0.05\right.$, Figure 3c). Furthermore, real-time PCR analysis showed knockdown of IncRNA XIST could markedly decrease the expression of many stemness-associated genes (Nanog, Oct-4 and SOX2) and surface antigens associated with cancer stem cells (CD24, CD44, CD133, CD155 and CD166) $\left({ }^{\star} P<0.05\right.$, Figure 3d). In addition, knockdown of IncRNA XIST significantly reduced the sphere formation in HCT116 and SW620 cells ( ${ }^{\star} P<0.05$, Figure $3 e$ ).

Knockdown of IncRNA XIST inhibits tumorigenesis and metastasis in vivo. Having demonstrated the biological effect of IncRNA XIST in vitro, we wondered whether IncRNA $\mathrm{XIST}$ could regulate tumorigenesis and metastasis in vivo. To test the effect of IncRNA XIST on tumorigenesis, cells (HCT116/sh-XIST and HCT116/sh-NC) were subcutaneously injected into the flank of nude mice, and the tumor volume was measured every week. At the end of the experiment, the mice were killed and the tumors were dissected out. The results showed that the volume and weight of tumors formed by HCT116/sh-XIST cells were obviously less than that formed by HCT116/sh-NC cells. The mean tumor volume was 356 and $743 \mathrm{~mm}^{3}$ for the HCT116/sh-XIST and HCT116/shNC groups, respectively, and the mean tumor weight was 0.75 and $0.38 \mathrm{~g}$ for the HCT116/sh-XIST and HCT116/sh-NC groups, respectively $\left({ }^{\star} P<0.05\right.$, Figure $\left.4 \mathrm{a}\right)$. Moreover, the results demonstrated that $>90 \%$ of the mice developed tumors when injected with $2.0 \times 10^{5}$ HCT116 sh-NC cells, whereas the tumor incidence reduced to $63.6 \%$ when mice were injected with the same number of HCT116 sh-XIST cells (group 1); the tumor incidence was $54.5 \%$ in the control group when the mice were injected with $1.0 \times 10^{5}$ cells, and the tumor incidence reduced to $27.2 \%$ in the sh-XIST group (group 2). Similarly, knockdown of IncRNA XIST dramatically reduced the tumor incidence from 36.3 to $0 \%$ when the mice were injected with $1.0 \times 10^{4}$ cells (group 3 ) (Figure $4 \mathrm{~b}$ ). The real-time PCR analysis confirmed the knockdown effect of IncRNA XIST in vivo ( ${ }^{\star} P<0.05$, Figure $\left.4 \mathrm{c}\right)$, and immunohistochemistry (IHC) analysis showed that knockdown of IncRNA XIST significantly reduced Ki-67 expression (Figure 4d). To explore the effect of IncRNA XIST on tumor metastasis, cells (sh-NC or sh-XIST, $2 \times 10^{6}$ cells/mouse) were injected into the tail vein of nude mice, and after 6 weeks the mice were killed and the lung and liver were exercised. Both the sh-NC and the sh-XIST groups did not form macroscopic metastases in the lung, and 6 of 11 mice in the sh-NC group formed macroscopic liver metastases, whereas only 1 of 11 mice in the sh-XIST group formed macroscopic liver metastases (Figure 4e). Compared with those injected with HCT116/sh-NC cells, mice injected with HCT116/sh-XIST cells formed significantly less micrometastases in the lung and liver. The mean micro lung metastatic nodules were 2.6 and 7.9 for the HCT116/sh-XIST and HCT116/sh-NC groups, respectively, and the mean micro liver metastatic nodules were 1.3 and 6.5 for the HCT116/shXIST and HCT116/sh-NC groups, respectively $\left({ }^{\star} P<0.05\right.$, Figure 4f).

IncRNA XIST acts as a ceRNA for miR-200b-3p to modulate ZEB1 expression in CRC cells. Recent studies have proposed that IncRNAs may participate in the ceRNA regulatory network. By using the online software program Starbase v2.0 (http://starbase.sysu.edu.cn/), we found that IncRNA XIST formed complementary base pairing with miR-200b-3p (Figure 5a). Knockdown of IncRNA XIST could 

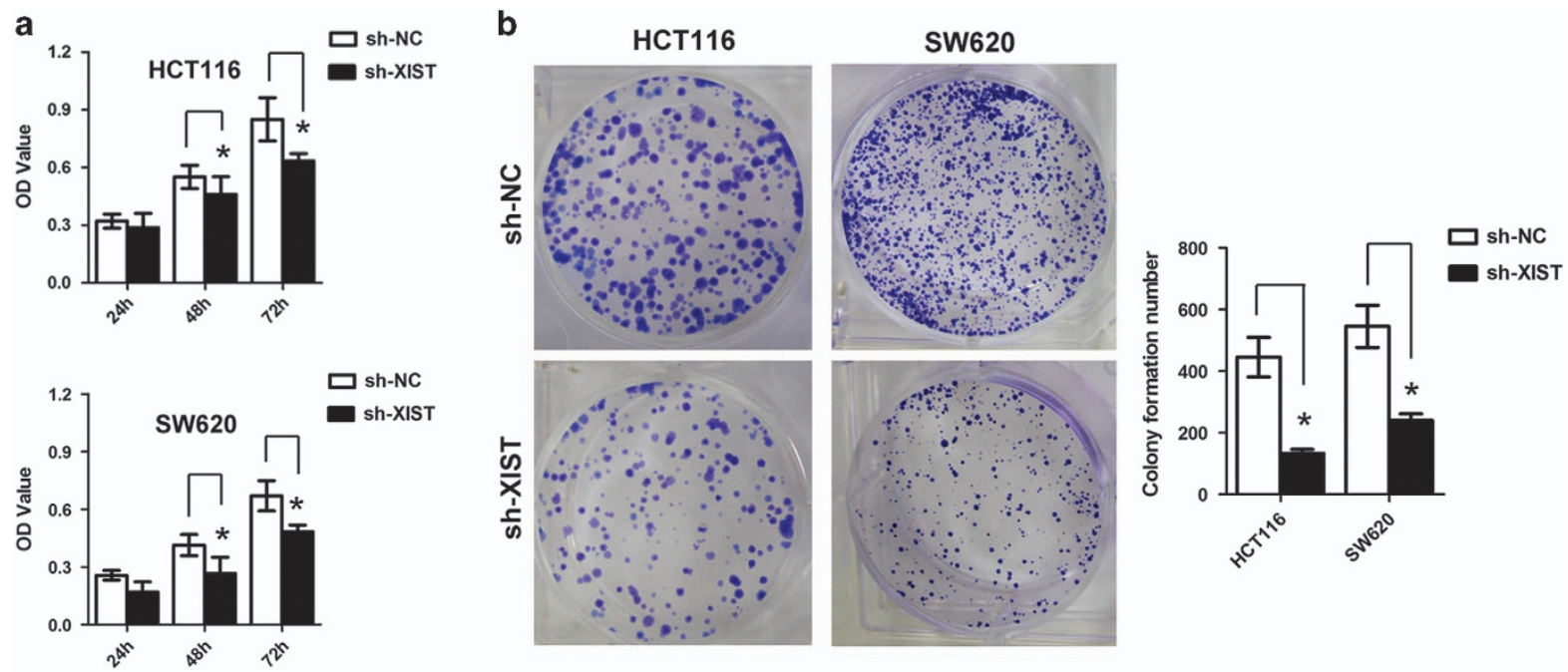

C

HCT116
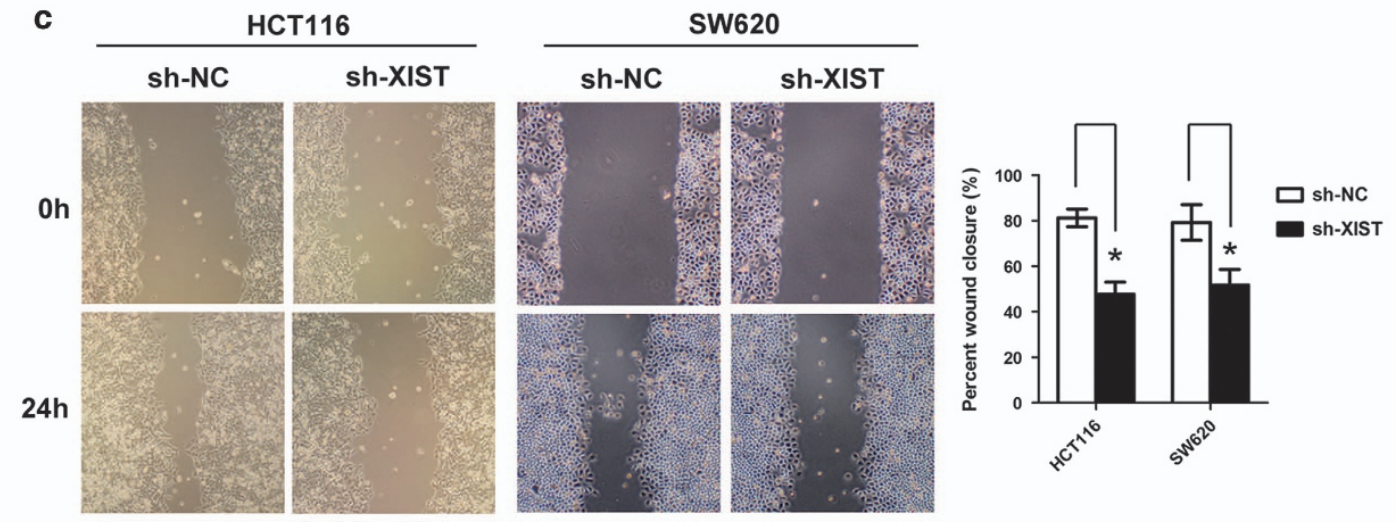

d

HCT116
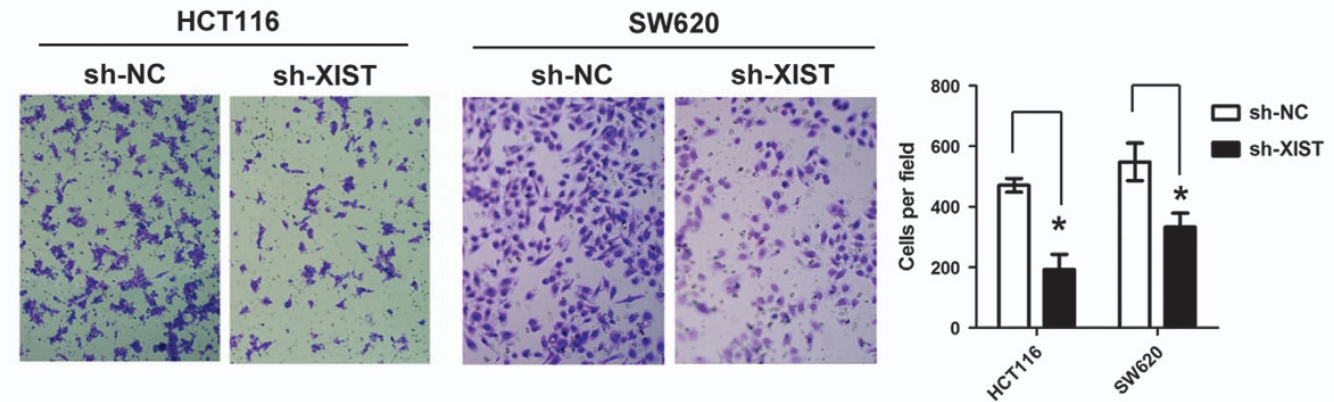

Figure 2 Knockdown of IncRNA XIST expression inhibits CRC cell growth, colony formation, migration and invasion in vitro. (a) Knockdown of IncRNA XIST inhibited cell proliferation as indicated by CCK-8 assays in HCT116 and SW620 cells ( $\left.{ }^{*} P<0.05\right)(n=3$ independent experiments). (b) Knockdown of IncRNA XIST inhibited colony formation as demonstrated by colony formation assays in HCT116 and SW620 cells $\left({ }^{*} P<0.05\right)$ ( $n=3$ independent experiments). (c) Knockdown of IncRNA XIST inhibited cell migration in HCT116 and SW620 cells as indicated by wound healing assays $\left({ }^{*} P<0.05\right)(n=3$ independent experiments). (d) Knockdown of IncRNA XIST inhibited cell invasion in HCT116 and SW620 cells as demonstrated by transwell assays $\left({ }^{*} P<0.05\right)(n=3$ independent experiments). Error bars represent the mean \pm S.D. values

significantly increase the expression of miR-200b-3p level in CRC cell lines HCT116 ( ${ }^{\star} P<0.05$, Figure $\left.5 b\right)$, and ectopic expression of miR-200b-3p could obviously reduce the expression of IncRNA XIST, whereas inhibition of miR-200b-3p could increase the expression of IncRNA XIST in CRC cells $\left({ }^{*} P<0.05\right.$, Figure $\left.5 \mathrm{~b}\right)$. To confirm the direct binding relationship between IncRNA XIST and miR-200b-3p, a luciferase activity assay was performed. We found that miR-200b-3p mimics markedly reduced the luciferase activities of pmirGLO-XIST-wt. However, no obvious reduction was observed in cells transfected with miR-200b-3p mimics and pmirGLO-XIST-wt $\left({ }^{\star} P<0.05\right.$, Figure $\left.5 \mathrm{c}\right)$. In addition, an inverse correlation was found between the expression of IncRNA XIST and miR-200b-3p in CRC tissues $\left(r=-0.73,{ }^{*} P=0.013\right.$, Figure $\left.5 \mathrm{~d}\right)$. We then explored the genes that were potentially regulated by miR-200b-3p. As IncRNA XIST could modulate EMT of CRC cells, we focused on $Z E B 1$, one of the genes that was reported to be involved in 
a

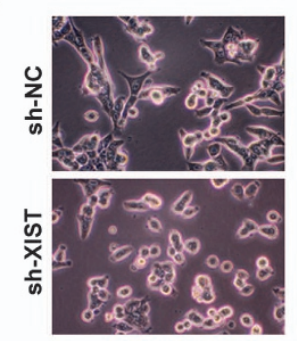

b

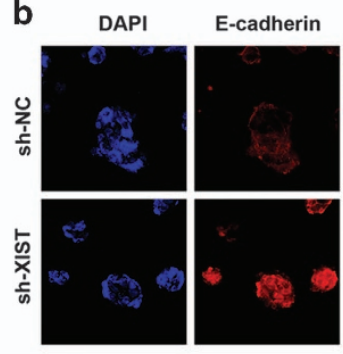

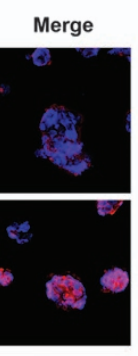

d
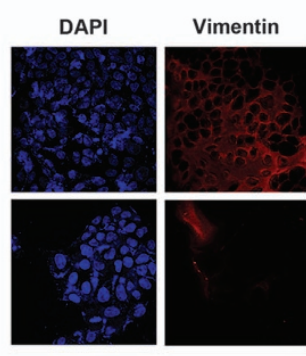

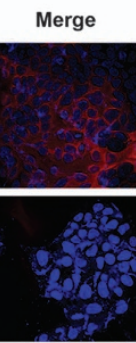

SW620
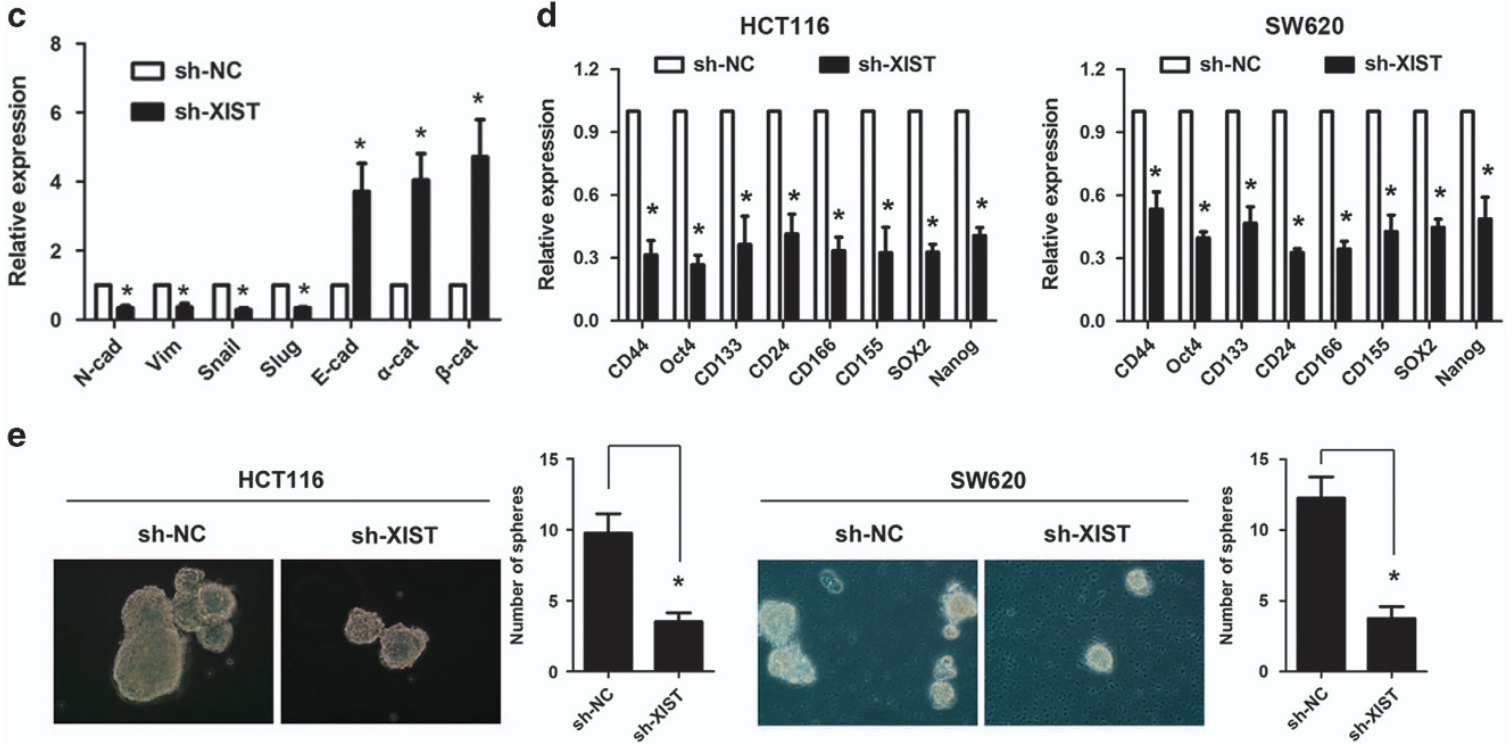

Figure 3 Knockdown of IncRNA XIST inhibits EMT and stem cell formation in CRC cells. (a) HCT116 cells underwent morphological change from a spindle shape to a rounded or cobblestone-like shape upon knockdown of IncRNA XIST. (b) Knockdown of IncRNA XIST significantly increased the expression of E-cadherin, whereas it decreased the expression of N-cadherin in SW620 cells as demonstrated by immunofluorescence. (c) Real-time PCR analysis showed that knockdown of IncRNA XIST significantly reduced the expression of mesenchymal markers ( $\mathrm{N}$-cadherin, Vimetin, Snail, Slug), whereas it increased the expression of epithelial markers (E-cadherin, $\alpha$-catenin, $\beta$-catenin) $\left({ }^{*} P<0.05\right)$ ( $n=3$ independent experiments). (d) Real-time PCR analysis showed knockdown of IncRNA XIST could markedly decrease the expression of many stemnessassociated genes (Nanog, Oct-4 and SOX2) and surface antigens associated with cancer stem cells (CD24, CD44, CD133, CD155 and CD166) $\left({ }^{*} P<0.05\right)(n=3$ independent experiments). (e) Knockdown of IncRNA XIST significantly reduced the sphere formation in HCT116 and SW620 cells ( $\left.{ }^{*} P<0.05\right)$. Error bars represent the mean \pm S.D. values

EMT. As shown in Figure 6a, there are several miR-200b-3pbinding sites in the $3^{\prime}$-UTR of ZEB1. To our interest, ectopic expression of miR-200b-3p could decrease whereas inhibition of miR-200b-3p could increase the expression of ZEB1 mRNA level in CRC cells ( ${ }^{\star} P<0.05$, Figure $\left.6 \mathrm{~b}\right)$. Luciferase activity assay showed that ectopic expression of miR-200b$3 p$ and/or knockdown of IncRNA XIST could significantly decrease the luciferase activity of the wild-type ZEB1 3'-UTR, but not of the mutant type ZEB1 3'-UTR; moreover, the reduced luciferase activity caused by IncRNA XIST knockdown could be restored by inhibition of miR-200b-3p $\left({ }^{\star} P<0.05\right.$, Figure 6c). Western blot analysis indicated that ectopic expression of miR-200b-3p and/or knockdown of IncRNA XIST significantly reduced the protein level of ZEB1, whereas inhibition of miR-200b-3p increased the protein level of ZEB1 in CRC cells (Figure 6d).

The miR-200b-3p/ZEB1 axis mediated the IncRNA XIST' oncogenic effect in CRC cells. IHC analysis showed that ZEB1 was overexpressed in CRC tissues (Figure 7a), and a positive correlation was observed between the expression of
ZEB1 and IncRNA XIST ( $r=0.433,{ }^{\star} P<0.001$, Figure $\left.7 \mathrm{~b}\right)$. Knockdown of IncRNA XIST could significantly reduce the mRNA level of ZEB1 in CRC cells, and the reduced level of ZEB1 mRNA induced by IncRNA XIST knockdown could be restored by ectopic expression of ZEB1 or inhibition of miR-200b-3p $\left({ }^{\star} P<0.05\right.$, Figure 7c). What's more, the suppression of tumor phenotype by knockdown of IncRNA XIST could be restored by ectopic expression of ZEB1 or inhibition of miR-200b-3p ( ${ }^{\star} P<0.05$, Figures $7 d$ and $e$ ).

\section{Discussion}

Mounting evidences showed that ncRNAs play important role in tumor pathology and might be used as diagnostic and therapeutic target. For example, nuclear-enriched abundant transcript 1 can function as a diagnostic and prognostic biomarker in CRC; ${ }^{14}$ HOTAIR is a negative prognostic factor not only in primary tumors, but also in the blood of CRC. ${ }^{15}$ Zhang et al. ${ }^{16}$ found that IncRNA CASC11 can interact with hnRNP-K and activate the WNT/ $\beta$-catenin pathway to promote growth and metastasis in CRC. Our previous study showed 
a

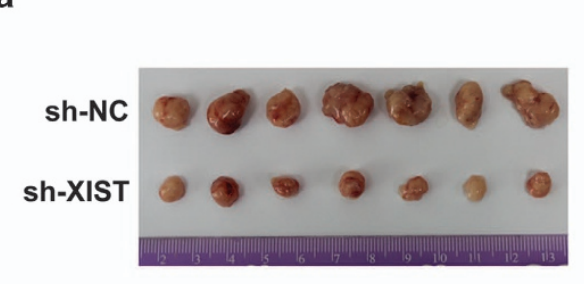

b

\begin{tabular}{|c|c|c|}
\hline $\begin{array}{l}\text { Experiment } \\
\text { group }\end{array}$ & $\begin{array}{l}\text { Cell number } \\
\text { injected }\end{array}$ & $\begin{array}{c}\text { Tumor } \\
\text { incidence }\end{array}$ \\
\hline sh-NC & $2 \times 10^{5}$ & $10 / 11(91.6 \%)$ \\
\hline \#1 L Lsh-XIST & $2 \times 10^{5}$ & $7 / 11$ (63.6\%) \\
\hline \multirow{2}{*}{$\# 2\left[\begin{array}{l}\mathrm{Sn}-\mathrm{N} \text { C } \\
\text { sh-XIST }\end{array}\right.$} & $1 \times 10^{5}$ & $6 / 11(54.5 \%)$ \\
\hline & $1 \times 10^{5}$ & $3 / 11(27.2 \%)$ \\
\hline \multirow{2}{*}{$\# 3\left[\begin{array}{l}\text { sh-NC } \\
\text { sh-XIST }\end{array}\right.$} & $2 \times 10^{4}$ & $4 / 11(36.3 \%)$ \\
\hline & $2 \times 10^{4}$ & $0 / 11(0.0 \%)$ \\
\hline
\end{tabular}
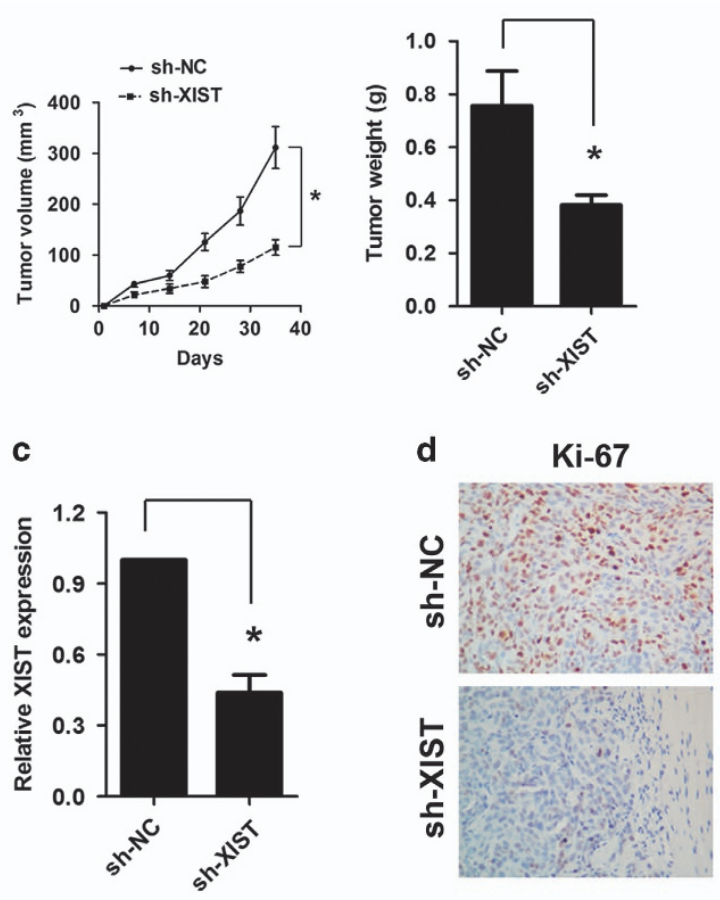

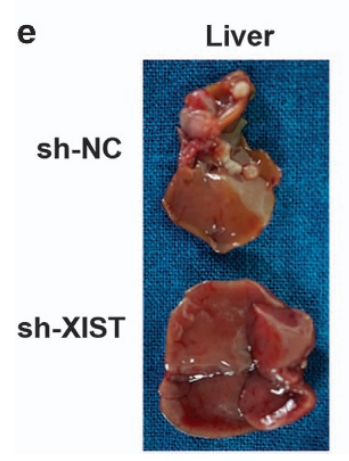

f
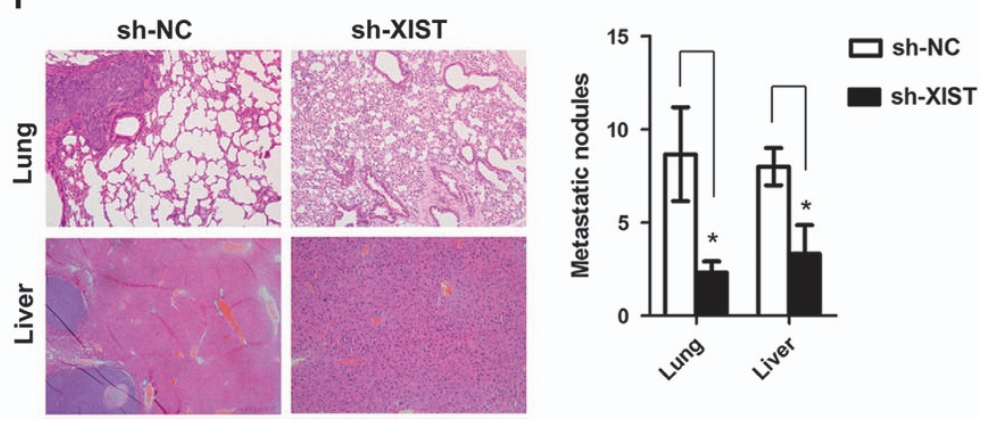

Figure 4 Knockdown of IncRNA XIST expression inhibits tumor growth and metastasis in vivo. (a) Knockdown of IncRNA XIST expression significantly inhibited tumor growth of HCT116 cells in nude mouse model. The tumor volume and tumor weight formed by HCT116 sh-XIST cells was significantly less than that of HCT116 sh-NC cells; the mean tumor volume was 356 and $743 \mathrm{~mm}^{3}$ for the HCT116/sh-XIST and HCT116/sh-NC groups, respectively, and the mean tumor weight was 0.75 and $0.38 \mathrm{~g}$ for the HCT116/sh-XIST and HCT116/sh-NC groups, respectively ( ${ }^{*} P<0.05$ ). (b) Of the mice, $91.6 \%$ developed tumors when injected with $2.0 \times 10^{5} \mathrm{HCT} 116$ sh-NC cells. The tumor incidence was $63.6 \%$ when mice were injected with $2.0 \times 10^{5} \mathrm{HCT} 116 \mathrm{sh}$-XIST cells (group 1); the tumor incidence was $54.5 \%$ when mice were injected with $1.0 \times 10^{5}$ sh-NC cells; the tumor incidence was $27.2 \%$ when mice were injected with $1.0 \times 10^{5}$ cells in the sh-XIST group (group 2); the tumor incidence was $36.3 \%$ and $0 \%$ when the mice were injected with $1.0 \times 10^{4}$ cells of sh-NC and sh-XIST, respectively (group 3). (c) Real-time PCR analysis showed that knockdown of IncRNA XIST significantly decreased the expression of IncRNA XIST in tumor tissues taken from the nude mice $\left({ }^{\star} P<0.05\right)$. (d) Immunohistochemistry analysis showed that knockdown of IncRNA XIST significantly reduced Ki-67 expression. (e) Knockdown of IncRNA XIST significantly reduced the macrometastases in the liver. Of the 11 mice in the sh-NC group, 6 formed macroscopic liver metastases, whereas only 1 of 11 mice in the sh-XIST group formed macroscopic liver metastases. (f) The mean micro lung metastatic nodules were 2.6 and 7.9 for the HCT116/sh-XIST and HCT116/sh-NC groups, respectively, and the mean micro liver metastatic nodules were 1.3 and 6.5 for the HCT116/sh-XISTand HCT116/sh-NC groups, respectively ( ${ }^{\star} P<0.05$ ). Error bars represent the mean \pm S.D. values

that knockdown of IncRNA XIST inhibited gastric cancer progression and metastasis through modulating the expression of EZH2. ${ }^{17}$ However, the role and molecular mechanism of IncRNA XIST in CRC remains unknown.

In this study, we found that IncRNA XIST expression was upregulated in CRC tissues than adjacent normal tissues. High IncRNA XIST expression was significantly associated with tumor size, lymph node invasion and clinical stage. Moreover, upregulation of IncRNA XIST was correlated with poor overall survival and might be used as an independent prognostic indicator for CRC patients. These results implicated that IncRNA XIST plays an important role in CRC progression. In accordance with our results, it has been found that IncRNA XIST plays an important role in different tumor types. For example, IncRNA XIST regulates PTEN expression by sponging miR-181a and promotes hepatocellular carcinoma progression; ${ }^{18}$ in another study, it was found that IncRNA XIST could promote pancreatic cancer proliferation through miR-133a/EGFR. ${ }^{19}$ However, other studies indicated that loss of IncRNA XIST is essential for some malignancies. 
a
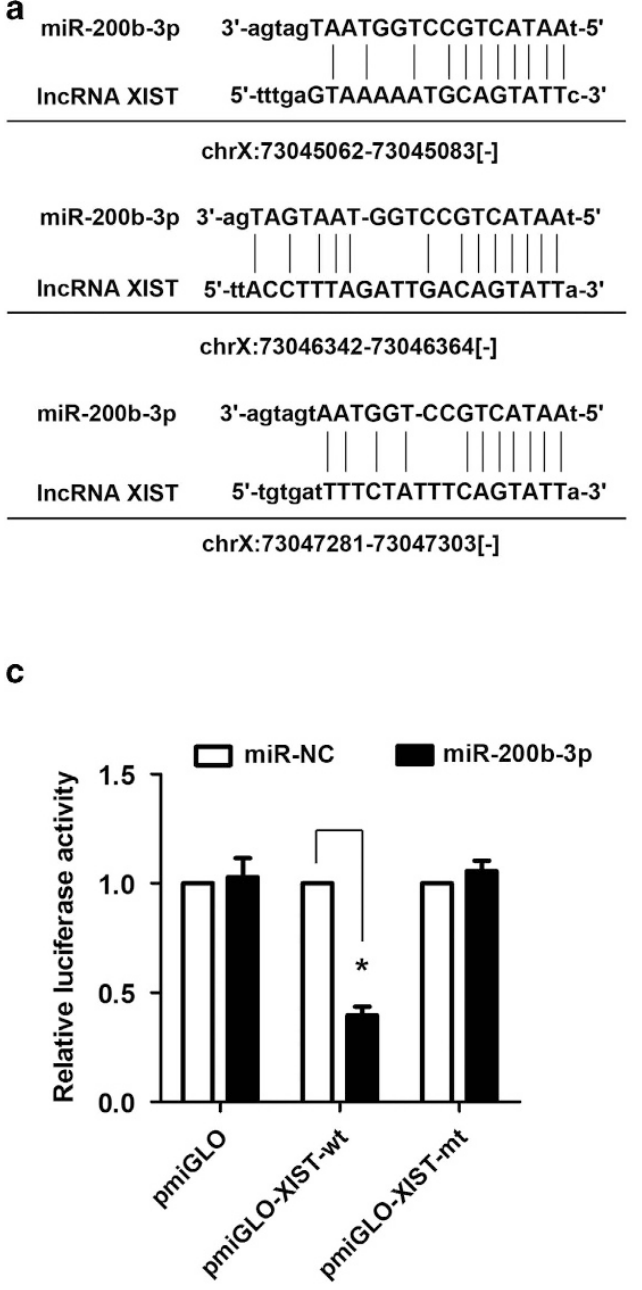

b
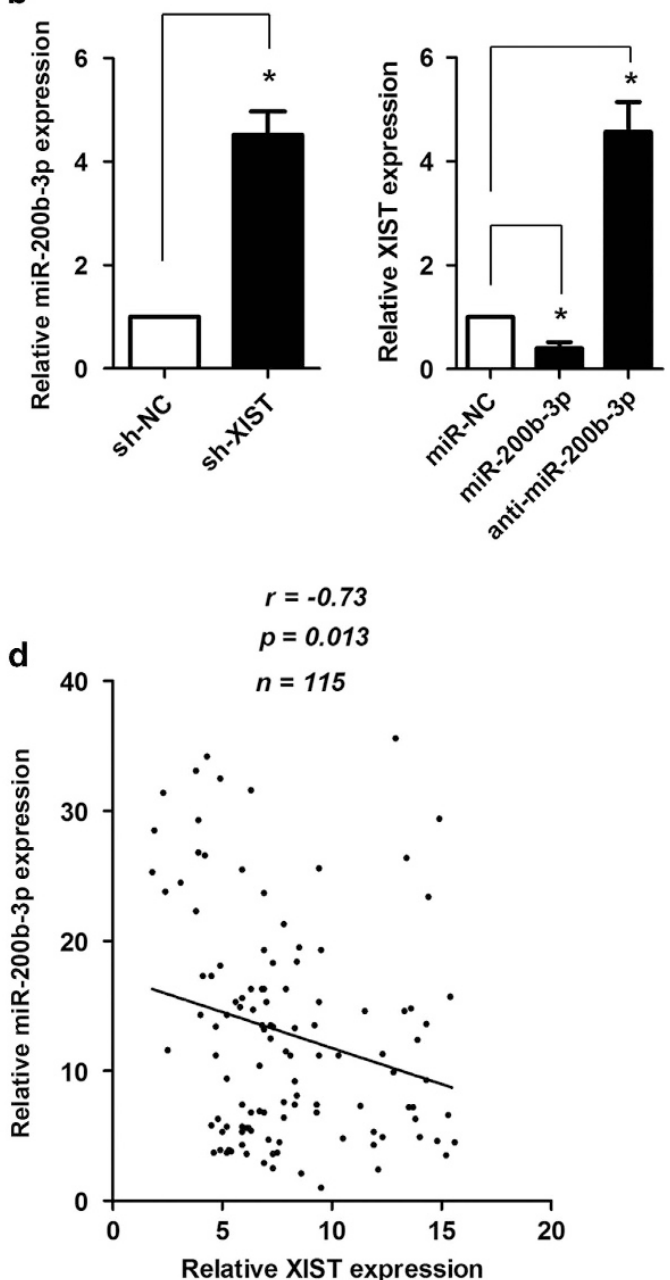

Figure 5 Reciprocal repression between IncRNA XIST and miR-200b-3p. (a) Schematic representation of the predicted target site for miR-200b-3p in IncRNA XIST. (b) Knockdown of IncRNA XIST increased miR-200b-3p expression in HCT116 cells; ectopic miR-200b-3p expression decreased IncRNA XIST expression, and inhibition of miR-200b-3p increased IncRNA XIST expression $\left({ }^{*} P<0.05\right)$. (c) Luciferase reporter assay in human embryonic kidney (HEK) 293T cells, co-transfected with the reporter plasmid (or the corresponding mutant reporter) and the indicated miRNAs. miR-200b-3p significantly decreased the luciferase activity in XIST-wt but not in XIST-mt $\left({ }^{\star} P<0.05\right)$. (d) The expression of IncRNA XIST was inversely correlated with the expression level of miR-200b-3p in CRC tissues $\left(r=-0.73,{ }^{*} P=0.013\right)$. Error bars represent the mean \pm S.D. values

For instance, Yildirim et al. ${ }^{20}$ reported that XIST deletion could induce hematologic cancer in female mice. Huang et al. ${ }^{21}$ demonstrated that XIST functions as a tumor suppressor in breast cancer. It seems that XIST gene is upregulated in a variety of non-sex-related tumors in both humans and mice, whereas it might be lost in some female cancers. The underlying mechanism for gender difference in XIST expression is complicated and needs further exploring. One exploration is that certain genes may be oncogenic in one cell/tissue whereas tumor suppressive in another, depending on the tumor type and cellular context.

Considering the function aspect, we found that knockdown of IncRNA XIST inhibited CRC cell proliferation and migration in vitro. Our data indicated that IncRNA XIST is involved in the regulation of EMT, and previous studies have demonstrated that EMT is an important step in tumor progression and metastasis. ${ }^{22,23}$ More importantly, we found that IncRNA XIST could affect the stemness of CRC cells, and this is in accordance with previous studies that have demonstrated that cancer stem cells are a key source of cancer metastasis and progression, and a direct link existed between the EMT and the gain of epithelial stem cell properties. ${ }^{24,25}$ These results indicated that IncRNA XIST regulated EMT and stem cell properties, leading to altered proliferation and invasion abilities, and finally affecting tumor growth and metastasis.

A growing number of studies have suggested the existence of a widespread interaction network involving ceRNAs, in which the ncRNAs can regulate miRNAs by binding to and titrating them off their binding sites on protein coding messengers. For example, IncRNA HULC is upregulated in liver cancer, and HULC overexpression can promote tumor progression in part through its inhibitory effects on the expression and activity of miR-372. ${ }^{26}$ Similar reports indicated 
a

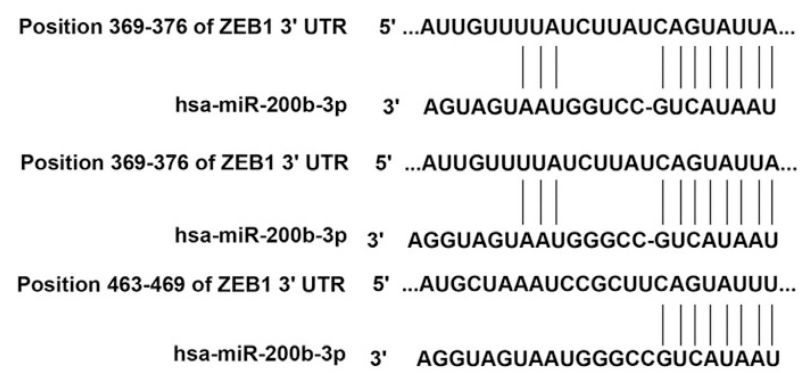

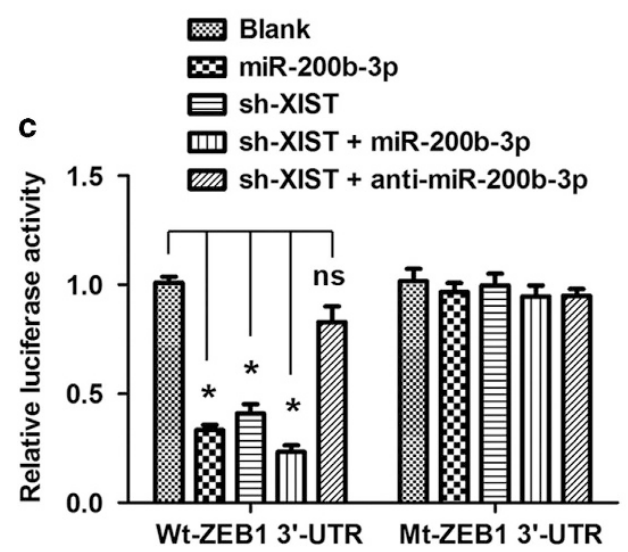
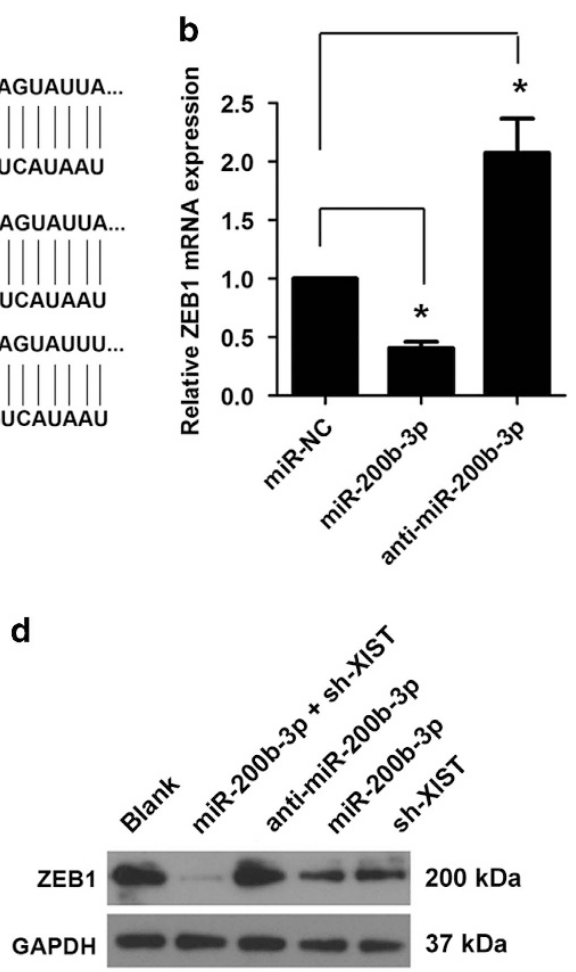

Figure 6 miR-200b-3p directly targets ZEB1 in CRC cells. (a) Schematic representation of the predicted target site for miR-200b-3p in the ZEB1 3'-UTR. (b) The ectopic expression of miR-200b-3p significantly decreased whereas inhibition of miR-200b-3p increased the expression of ZEB1 mRNA level in CRC cells $\left({ }^{*} P<0.05\right)$. (c) Luciferase activity assay in the wild type and mutant type when transfected with different vectors $\left({ }^{*} P<0.05\right)$. (d) ZEB1 protein level in HCT116 cells following ectopic expression of miR-200b-3p and/or knockdown of IncRNA XIST and inhibition of miR-200b-3p. Error bars represent the mean \pm S.D. values

that $\mathrm{H} 19$ functions as ceRNA to modulate let-7 and promotes breast cancer stem cell maintenance. ${ }^{27}$ Liu et al. ${ }^{28}$ revealed a reciprocal repression between loc285194 and miR-211 in colon cancer. In this study, we used bioinformatics databases (Starbase v2.0, miRcode and RNAhybrid) and identified several miRNAs that might interact with IncRNA XIST. To our interest, miR-200b-3p was one of the miRNAs that could be potentially regulated by IncRNA XIST, and miR-200b-3p has been found to be downregulated in CRC and other tumors. ${ }^{29,30}$ The regulating relationship between miR-200b$3 p$ and IncRNA XIST was confirmed by the following evidences: (1) miR-200b-3p expression was markedly increased upon knockdown of IncRNA XIST; (2) ectopic expression of miR-200b-3p obviously decreased the expression of IncRNA XIST, whereas inhibition of miR-200b-3p increased the expression of IncRNA XIST; (3) an inverse association existed between the expression level of IncRNA XIST and miR-200b-3p in CRC tissues; (4) luciferase activity assay confirmed that miR-200b-3p could directly bind to the 3 -end of IncRNA XIST. Similar to our results, a recent report indicated that IncRNA XIST functions as a molecular sponge for miR-139-5p in hepatocellular carcinoma. ${ }^{31}$ This implies that IncRNA XIST may interact with different miRNAs depending on tumor types.

ZEB1 is an important regulator of EMT and cell invasion in different tumor types. ${ }^{32,33}$ In this study, we found that ZEB1 was directly targeted by miR-200b-3p. IncRNA XIST could indirectly regulate ZEB1 expression by way of sponging to miR-200b-3p. The tumor suppressive effect of IncRNA knockdown could be restored by re-expression of ZEB1 in CRC cells. In addition, we found that ZEB1 was upregulated and positively associated with IncRNA XIST expression in CRC. This is in line with previous reports that indicated ZEB1 confers EMT, stem-like properties and stimulates tumor progression. ${ }^{34,35}$ It has been reported that some IncRNAs can influence transcription at enhancers and promoters. We determined whether IncRNA XIST could modulate the transactivation of ZEB1 mRNA. The promoter of ZEB1 was cloned upstream of a luciferase reporter gene, and the resultant construct was co-transfected with IncRNA XIST in CRC cells. However, the result showed that IncRNA XIST did not affect the transactivation of the ZEB1 promoter (data not shown), implying that IncRNA XIST might regulate ZEB1 after it is transcribed. Taken together, these data showed that IncRNA XIST functioned as a ceRNA for miR-200b-3p to regulate ZEB1 expression.

In conclusion, we provided the first evidence that IncRNA XIST was overexpressed in CRC tissues, and IncRNA XIST upregulated the miR-200b-3p target gene ZEB1 by way of competitively 'sponging' miR-200b-3p, and then promoted cell proliferation, invasion, EMT and stem cell formation in vitro as well as tumorigenesis and metastasis in vivo (Figure 8). 
a

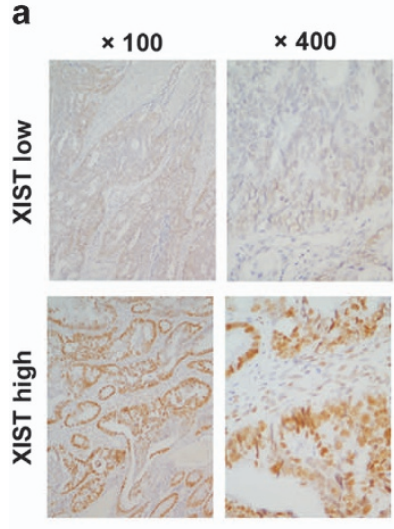

b

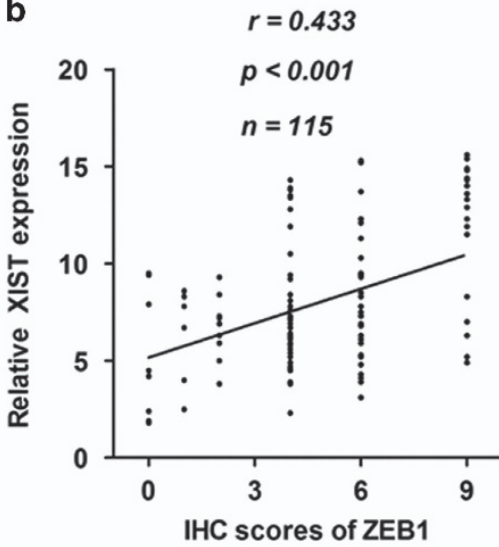

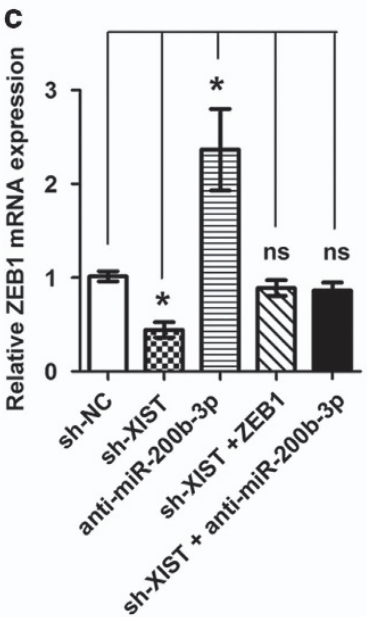

sh-NC

$\infty$ sh-XIST

是 anti-miR-200b-3p

四 sh-XIST + ZEB1

sh-XIST + anti-miR-200b-3p

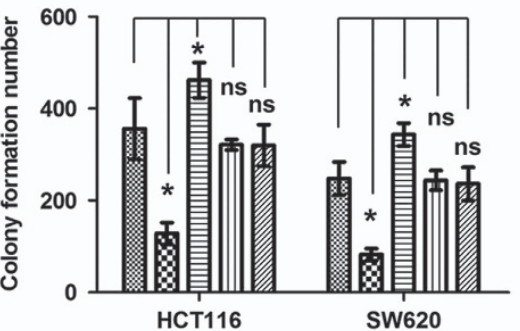

e

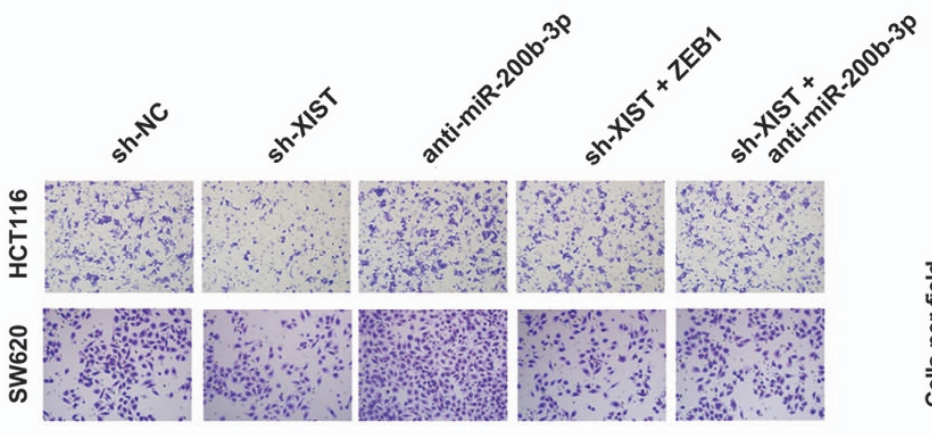

sh-NC

$\$ s h-X I S T$

曰 anti-miR-200b-3p

四 sh-XIST + ZEB1

In sh-XIST + anti-miR-200b-3p

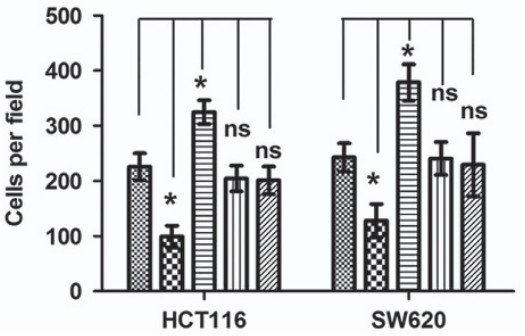

Figure 7 ZEB1 expression mediated the biological effects exerted by IncRNA XIST. (a) The expression of ZEB1 in CRC tissues detected by IHC. (b) The correlation between the expression of IncRNA XIST and ZEB1 $\left(r=0.433,{ }^{*} P<0.001\right)$. (c) ZEB1 mRNA level following treatment of different vectors $\left.{ }^{*} P<0.05\right)$. (d) Colony formation assay following treatment of different vectors $\left({ }^{*} P<0.05\right)$ ( $n=3$ independent experiments). (e) Cell invasion following treatment of different vectors $\left({ }^{*} P<0.05\right)(n=3$ independent experiments). Error bars represent the mean \pm S.D. values

IncRNA XIST might be used as a prognostic biomarker for CRC patients. As IncRNA XIST loss might induce hematopoietic malignancies and other X-chromosome gene activation events that may cause gene-dosage-associated pathologies in females, ${ }^{20}$ the application of targeting XIST should be individualized in CRC patients, it might be more feasible in male CRC patients and should be used with caution in female patients.

\section{Materials and Methods}

Human tissue samples. CRC specimens and adjacent normal tissues were obtained from 115 patients who received surgery in SUSYCC from May 2008 to July 2012. All the samples were confirmed by pathologists. None of the patients receive any treatment before surgery. Each patient was returned for follow-up visit with an interval of 3 months. The clinical and pathological characteristics were obtained from patients' history record. Overall survival time was defined as the date of operation to the date of death or last contact. This study has been approved by the institutional ethics review board of Sun Yat-sen University Cancer Center (SYSUCC) 


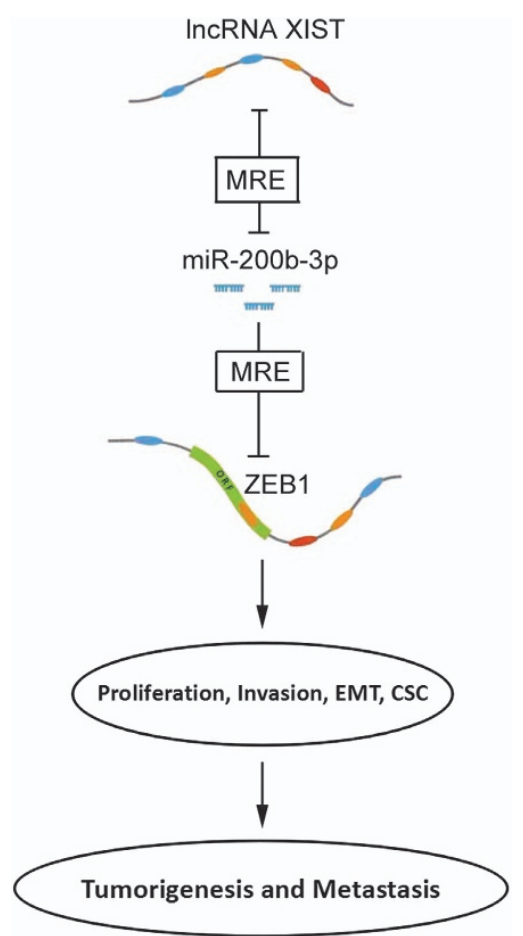

Figure 8 The functional model underlying the mechanism of IncRNA XIST on CRC tumorigenesis and metastasis. IncRNA XIST sponging to miR-200b-3p through the MRE (microRNA response element); it thus acts as a ceRNA to regulate the expression of ZEB1 and modulate the proliferation, invasion, EMT and stem cell properties in vitro and tumorigenesis and metastasis in vivo

(Guangzhou, China) and all patients provided written informed consent before participating in this study.

Cell lines. Human CRC cell lines including HCT116, HT-29, SW620, SW480, DLD-1, RKO, LoVo, the normal colon epithelial cell line CCD-116CoN and the human embryonic kidney (HEK) 293T cell were obtained from the American Type Culture Collection (Manassas, VA, USA). Cells were cultured and stored according to the provider's instructions, and were routinely authenticated every 6 months by cell morphology monitoring and growth curve analysis.

RNA extraction and real-time PCR analysis. Total RNA was extracted from tissues and cells with Trizol reagent (Takara, Otsu, Japan) according to the manufacturer's instructions. NanoDrop ND-2000 spectrophotometer (Thermo Scientific, Wilmington, DE, USA) was used to measure the RNA concentration and purity. The reverse transcription for IncRNA XIST and ZEB1 was performed with the High-Capacity cDNA Reverse Transcription Kit (Applied Biosystems, Foster City, CA, USA). RNA ( $2 \mu \mathrm{g})$ from each tissue and cell sample was used to synthesize cDNA using a reverse transcription kit (Takara). Real-time PCR was performed using SYBR Green Real-Time PCR MasterMix (Toyobo, Osaka, Japan), and GAPDH was used as the reference. The primers used for the real-time PCR are listed in Supplementary Table S3. The All-in-One miRNA qRT-PCR Detection Kit (GeneCopoeia, Rockville, Montgomery, USA) was used to detect the miR-200b-3p level according to the provider's instructions; U6 small RNA was used as the positive control. Real-time PCR was performed with the Bio-Rad CFX96 qPCR system (Hercules, CA, USA) and fold changes were determined using the relative quantification $2^{-\triangle \triangle} \mathrm{CT}$ method.

Lentivirus production and infection. The details for constructing stable knockdown cells of IncRNA XIST can be found in our previously published study. ${ }^{17}$

Cell transfections. Cell transfections were performed according to the method described previously. ${ }^{36}$ Briefly, the cells were cultured in a 6-well plate the day before transfection. Cell transfections were performed using Lipofectamine 2000 (Invitrogen, Carlsbad, CA, USA) with a final concentration of $50 \mathrm{nM}$ and collected for assays after $48 \mathrm{~h}$. The miR-200b-3p mimic, miR-200b-3p inhibitor and negative control (NC) oligonucleotides were purchased from Ribobio (Guangzhou, China). To rescue the expression of ZEB1, cells were co-transfected with a pcDNA3.1-ZEB1 plasmid that contained the coding sequences but lacked the $3^{\prime}$-UTR of ZEB1.

Cell proliferation assay. Cell proliferation was performed using CCK-8 assays. Briefly, $1 \times 10^{3}$ cells were cultured in a 96-well plate at $37^{\circ} \mathrm{C}$. Plates were incubated at $37^{\circ} \mathrm{C}$ for $2 \mathrm{~h}$ after each well was added with $10 \mu$ l CCK-8 solution. Then, the spectrophotometric absorbance was measured at $570 \mathrm{~nm}$ for each sample. All the experiments were performed in triplicate and repeated 3 times, and the mean value was calculated.

Cell colony formation assay. Cells were trypsinized and suspended in RPMI-1640 medium (GIBCO, Grand Island, NE, USA) with $10 \% \mathrm{FBS}$, the cells were then seeded in 6-well plates in triplicate and cultured in a humidified atmosphere containing $5 \% \mathrm{CO}_{2}$ at $37^{\circ} \mathrm{C}$ for 14 days. Cell colonies were washed with PBS, fixed with methanol for $30 \mathrm{~min}$ and stained with $0.1 \%$ crystal violet $(1 \mathrm{mg} / \mathrm{ml})$ for $20 \mathrm{~min}$. Colonies containing $>50$ cells were counted, and the mean colony numbers were calculated.

Cell migration and invasion assay. Cell migration and invasion potential was assessed by wound healing and transwell assays, respectively. For transwell assay, cells were trypsinized and $1 \times 10^{5}$ cells in $100 \mu$ l of serum-free RPMI-1640 medium were plated into the upper chamber. RPMI-1640 medium $(500 \mu \mathrm{l})$ supplemented with $20 \%$ FBS was added to the lower chamber. After culturing for $22 \mathrm{~h}$, cells that had invaded the lower chamber were fixed with methanol and stained with $0.1 \%$ crystal violet. The number of invaded cells was observed by using an inverted microscope (magnification $\times 200$ ) and calculated by counting five random views. For wound healing assay, cells were trypsinized and seeded in 6-well plates, and $12 \mathrm{~h}$ later an artificial wound was created by using a $200 \mu \mathrm{l}$ pipette tip. The wound was observed after $24 \mathrm{~h}$ and imaged under a microscope. The fraction of cell coverage across the line was measured for the migration rate.

Tumorigenesis and metastasis assays. The 5-week-old Female BABL/c athymic nude mice were obtained from the Beijing Vital River Laboratory Animal Technology Co., Ltd (Beijing, China). For tumorigenesis analysis, $1 \times 10^{6}$ cells stable knockdown of IncRNA XIST (sh-XIST) or negative control cells (sh-NC) were inoculated into the right flanks of each mouse. Tumor diameter $(\mathrm{mm})$ was measured every week, and the tumor volumes were calculated using the formula $V=$ (shortest diameter $)^{2} \times($ longest diameter $) \times 0.5$. After 35 days, the mice were killed and the tumors were exercised. For metastasis analysis, $2 \times 10^{6}$ cells were inoculated into the tail vein of each mouse, and after 6 weeks the mice were killed and the lung and liver were exercised and paraffin embedded. Consecutive sections $(4 \mu \mathrm{m})$ were made using the tissues, and stained with hematoxylin-eosin. The micrometastases in the lungs and livers were evaluated by a dissecting microscope. All the animal experiments were performed according to the National Institutes of Health animal use guidelines on the use of experimental animals.

Vector construction and luciferase reporter assay. The $3^{\prime}$-end fragment from IncRNA XIST containing the predicted miR-200b-3p-binding site was amplified using PCR and subcloned into a pmirGLOluciferase Target Expression Vector (Promega, Madison, WI, USA) to form the XIST wild-type (pmirGLO-XIST-wt) vector. The mutated miR-200b-3p-binding sequence was constructed that was named as pmirGLO-XIST-mt vector. The HEK 293T cells were co-transfected with PrirGLO, pmirGLO-XIST-wt, prirGLO-XIST-mt and miR-200b-3p mimics or negative control using Lipofectamine 2000 , and the relative luciferase activity was measured using the Dual-Luciferase Reporter Assay Kit (Promega) after $48 \mathrm{~h}$.

Western blot analyses. Western blot analysis was performed using a method described previously. ${ }^{36}$ The primary antibodies used in this study were as follows: ZEB1 (ABE596), GAPDH (2118 L), E-cadherin (3199 S) and N-cadherin (14215 S).

Statistical analyses. All statistical analyses were performed using the SPSS (version 16.0, SPSS Inc., Chicago, IL, USA) or GraphPad Prism 5.0 (GraphPad Software, Inc, CA, USA). The results were expressed as mean \pm S.D. Survival analysis was evaluated using the Kaplan-Meier method and assessed using the 
log-rank test. Student's t-test or one-way ANOVA was used to analyze the in vitro and in vivo data. A $P$-value of $<0.05$ was considered to be statistically significant.

\section{Conflict of Interest}

The authors declare no conflict of interest.

Acknowledgements. This study was supported by the National Natural Science Foundation of China (No. 81372570; No. 81602053), the Natural Science Foundation of Guangdong Province (No. 2014A030312015; No. 2016A030310195), the Science and Technology Program of Guangdong (No. 2015B020232008), the Science and Technology Program of Guangzhou (No. 15570006, 158100066) and the fourth outstanding young talents training plan of Sun Yat-sen University Cancer Center (No. PT04141001).

\section{Author contributions}

$\mathrm{R}-\mathrm{HX}$ and $\mathrm{H}-\mathrm{QJ}$ conceived and designed the project. D-LC, L-ZC and Y-XL carried out most of the experiments. D-SZ and Z-LZ collected the clinical and pathological data. Z-ZP collected the tissue samples. PH supervised the experiments and revised the manuscript. F-HW and Y-HL performed the statistical analysis. D-LC wrote the manuscript. All authors read and approved the final manuscript.

\section{Publisher's Note}

Springer Nature remains neutral with regard to jurisdictional claims in published maps and institutional affiliations.

1. Torre LA, Bray F, Siegel RL, Ferlay J, Lortet-Tieulent J, Jemal A. Global cancer statistics, 2012. CA Cancer J Clin 2015; 65: 87-108.

2. Chaffer CL, Weinberg RA. A perspective on cancer cell metastasis. Science 2011; 331: 1559-1564.

3. Esteller M. Non-coding RNAs in human disease. Nat Rev Genet 2011; 12: 861-874.

4. Wang KC, Chang HY. Molecular mechanisms of long noncoding RNAs. Mol Cell 2011; 43: 904-914.

5. Guttman M, Donaghey J, Carey BW, Garber M, Grenier JK, Munson G et al. lincRNAs act in the circuitry controlling pluripotency and differentiation. Nature 2011; 477: 295-300.

6. Loewer S, Cabili MN, Guttman M, Loh YH, Thomas K, Park IH et al. Large intergenic non-coding RNA-RoR modulates reprogramming of human induced pluripotent stem cells. Nat Genet 2010; 42: 1113-1117.

7. Khaitan D, Dinger ME, Mazar J, Crawford J, Smith MA, Mattick JS et al. The melanomaupregulated long noncoding RNA SPRY4-IT1 modulates apoptosis and invasion. Cancer Res 2011; 71: 3852-3862.

8. Wang KC, Yang YW, Liu B, Sanyal A, Corces-Zimmerman R, Chen Y et al. A long noncoding RNA maintains active chromatin to coordinate homeotic gene expression. Nature 2011; 472 : 120-124.

9. Tsai MC, Manor O, Wan Y, Mosammaparast N, Wang JK, Lan F et al. Long noncoding RNA as modular scaffold of histone modification complexes. Science 2010; 329: 689-693.

10. Ma Y, Yang Y, Wang F, Moyer MP, Wei Q, Zhang P et al. Long non-coding RNA CCAL regulates colorectal cancer progression by activating Wnt/beta-catenin signalling pathway via suppression of activator protein 2alpha. Gut 2016; 65: 1494-1504.

11. Brown CJ, Ballabio A, Rupert JL, Lafreniere RG, Grompe M, Tonlorenzi R et al. A gene from the region of the human $X$ inactivation centre is expressed exclusively from the inactive $X$ chromosome. Nature 1991; 349: 38-44.

12. Weakley SM, Wang $\mathrm{H}$, Yao Q, Chen $\mathrm{C}$. Expression and function of a large non-coding RNA gene XIST in human cancer. World J Surg 2011; 35: 1751-1756.

13. Yao Y, Ma J, Xue Y, Wang P, Li Z, Liu J et al. Knockdown of long non-coding RNA XIST exerts tumor-suppressive functions in human glioblastoma stem cells by up-regulating miR-152. Cancer Lett 2015; 359: 75-86.

14. Wu Y, Yang L, Zhao J, Li C, Nie J, Liu F et al. Nuclear-enriched abundant transcript 1 as a diagnostic and prognostic biomarker in colorectal cancer. Mol Cancer 2015; 14: 191.

15. Svoboda M, Slyskova J, Schneiderova M, Makovicky P, Bielik L, Levy M et al. HOTAIR long non-coding RNA is a negative prognostic factor not only in primary tumors, but also in the blood of colorectal cancer patients. Carcinogenesis 2014; 35: 1510-1515.

16. Zhang Z, Zhou C, Chang Y, Hu Y, Zhang F, Lu Y et al. Long non-coding RNA CASC11 interacts with hnRNP-K and activates the WNT/beta-catenin pathway to promote growth and metastasis in colorectal cancer. Cancer Lett 2016; 376: 62-73.
17. Chen DL, Ju HQ, Lu YX, Chen LZ, Zeng ZL, Zhang DS et al. Long non-coding RNA XIST regulates gastric cancer progression by acting as a molecular sponge of miR-101 to modulate EZH2 expression. J Exp Clin Cancer Res 2016; 35: 142.

18. Chang S, Chen B, Wang X, Wu K, Sun Y. Long non-coding RNA XIST regulates PTEN expression by sponging miR-181a and promotes hepatocellular carcinoma progression. BMC Cancer 2017; 17: 248

19. Wei W, Liu Y, Lu Y, Yang B, Tang L. LncRNA XIST promotes pancreatic cancer proliferation through miR-133a/EGFR. J Cell Biochem 2017; 118: 3349-3358.

20. Yildirim E, Kirby JE, Brown DE, Mercier FE, Sadreyev RI, Scadden DT et al. Xist RNA is a potent suppressor of hematologic cancer in mice. Cell 2013; 152: 727-742.

21. Huang YS, Chang CC, Lee SS, Jou YS, Shih HM. Xist reduction in breast cance upregulates AKT phosphorylation via HDAC3-mediated repression of PHLPP1 expression. Oncotarget 2016; 7: 43256-43266.

22. Kraljevic Pavelic S, Sedic M, Bosnjak H, Spaventi S, Pavelic K. Metastasis: new perspectives on an old problem. Mol Cancer 2011; 10: 22.

23. Thiery JP, Acloque H, Huang RY, Nieto MA. Epithelial-mesenchymal transitions in development and disease. Cell 2009; 139: 871-890.

24. Chen T, You Y, Jiang H, Wang ZZ. Epithelial-mesenchymal transition (EMT): a biological process in the development, stem cell differentiation, and tumorigenesis. J Cell Physiol 2017 (doi:10.1002/icp.25797; e-pub ahead of print).

25. Mani SA, Guo W, Liao MJ, Eaton EN, Ayyanan A, Zhou AY et al. The epithelial-mesenchymal transition generates cells with properties of stem cells. Cell 2008; 133: 704-715.

26. Wang J, Liu X, Wu H, Ni P, Gu Z, Qiao Y et al. CREB up-regulates long non-coding RNA, HULC expression through interaction with microRNA-372 in liver cancer. Nucleic Acids Res 2010; 38: 5366-5383.

27. Peng F, Li TT, Wang KL, Xiao GQ, Wang JH, Zhao HD et al. H19/let-7/LIN28 reciprocal negative regulatory circuit promotes breast cancer stem cell maintenance. Cell Death Dis 2017; 8: e2569.

28. Liu Q, Huang J, Zhou N, Zhang Z, Zhang A, Lu Z et al. LncRNA loc285194 is a p53-regulated tumor suppressor. Nucleic Acids Res 2013; 41: 4976-4987.

29. Diaz T, Tejero R, Moreno I, Ferrer G, Cordeiro A, Artells R et al. Role of miR-200 family members in survival of colorectal cancer patients treated with fluoropyrimidines. J Surg Oncol 2014; 109: 676-683.

30. Wu J, Cui H, Zhu Z, Wang L. MicroRNA-200b-3p suppresses epithelial-mesenchymal transition and inhibits tumor growth of glioma through down-regulation of ERK5. Biochem Biophys Res Commun 2016; 478: 1158-1164.

31. Mo Y, Lu Y, Wang P, Huang S, He L, Li D et al. Long non-coding RNA XIST promotes cell growth by regulating miR-139-5p/PDK1/AKT axis in hepatocellular carcinoma. Tumour Biol 2017; 39: 1010428317690999.

32. Krebs AM, Mitschke J, Lasierra Losada M, Schmalhofer O, Boerries M, Busch $\mathrm{H}$ et al. The EMT-activator Zeb1 is a key factor for cell plasticity and promotes metastasis in pancreatic cancer. Nat Cell Biol 2017; 19: 518-529.

33. Ma J, Zhan Y, Xu Z, Li Y, Luo A, Ding F et al. ZEB1 induced miR-99b/let-7e/miR-125a cluster promotes invasion and metastasis in esophageal squamous cell carcinoma. Cancer Lett 2017; 398: 37-45.

34. Zhou $\mathrm{C}$, Jiang $\mathrm{H}$, Zhang $Z$, Zhang $\mathrm{G}$, Wang $\mathrm{H}$, Zhang $\mathrm{Q}$ et al. ZEB1 confers stem cell-like properties in breast cancer by targeting neurogenin-3. Oncotarget 2017 (doi:10.18632/oncotarget.17077; e-pub ahead of print).

35. Zhang J, Zhou C, Jiang H, Liang L, Shi W, Zhang Q et al. ZEB1 induces ER-alpha promoter hypermethylation and confers antiestrogen resistance in breast cancer. Cell Death Dis 2017; 8: e2732.

36. Chen DL, Wang DS, Wu WJ, Zeng ZL, Luo HY, Qiu MZ et al. Overexpression of paxillin induced by miR-137 suppression promotes tumor progression and metastasis in colorectal cancer. Carcinogenesis 2013; 34: 803-811.

Cell Death and Disease is an open-access journal published by Nature Publishing Group. This work is licensed under a Creative Commons Attribution 4.0 International License. The images or other third party material in this article are included in the article's Creative Commons license, unless indicated otherwise in the credit line; if the material is not included under the Creative Commons license, users will need to obtain permission from the license holder to reproduce the material. To view a copy of this license, visit http://creativecommons.org/licenses/by/4.0/

(C) The Author(s) 2017 